In this new earthquake springs are said to have burst out on the side of Mount Sipylus.

32, St. George's Square, S.W., August 9

\section{New Biological Term}

IN writing certain parts of a book on water-beetles, I find myself frequently desirous of indicating briefly but emphatically that some particular genus I may be mentioning consists of only a single species. If we take a rational or theoretical view of classification rather than an empirical one, it must be admitted that a genus consisting of only one species is almost as great an anomaly as a species that should consist of a single individual; and a special term to indicate the fact would be desirable. $\mathrm{Mr}$. Pascoe has suggested to me that the expression "monotypical genus" meets the want : but I am not satisfied with this, for in the first place it is a phrase, not a word ; and in the second place the use of the "typical" interferes with concentration of thought by the introduction of an alien suggestion. I therefore propose to use either the word "autogenus" or the word "monogenus" for the purpose, and on the whole prefer the former. Perhaps some one else may be able to suggest a better term, and I shall be very glad of an expression of opinion on the point.

Thornhill, Dumfriesshire

D. SHARP

\section{Depraved Taste in Animals}

Your correspondent, Mr, Nicols, draws attention this week to what he terms the "depraved taste" for tobacco exhibited by several individuals of that species of Phalangistidæ known as the koala.

Whilst in Australia some years ago I myself remarked the same propensity amongst numerous wild specimens of the Fharcolarctos cinereus, in an abandoned tobacco-clearing not far from my residence, and, like $\mathrm{Mr}$. Nicols, I also observed that no ill effects seemed to follow the consumption of the tobacco by the Koalæ. Now since the Phalangistidx I had the opportunity of observing were perfectly wild, I cannot agree with $\mathrm{Mr}$. Nicols that their taste for tobacco is a depraved one, although the desire for spirits which he mentions is of course decidedly unnatural.

These observations induced me to make several analyses of the Victorian tobacco, with the result of isolating an hitherto undiscovered vegetable alkaloid. A detailed account of my various experiments is contained in a paper read by me before the Melbourne Medical and Chemical Society, and printed in the fourteenth volume of the Society's Transactions.

St. Bartholomew's Hospital, E.C., August i4

$$
\text { F. R. GreEnwood }
$$

Firing a Tallow Candle through a Deal Board

WILL the writer of "Physics without Apparatus" be good enough to specify the conditions of sticcess for the above experiment?

Birmingham and Midland Institute, August 9

[Set up a $\frac{1}{2}$-inch or $\frac{8}{4}$-inch plank of deal in the ground. It should be 6-8 inches wide. IRam small charge of gunpowder into gun with wad. Select a dip candle just fitting bore; cut down to about 5 inches long, with flat end. Be very particular to ram it down well ; for if there is air space between it and the wad there is risk of bursting gun. Take care that the rest of barrel is cleared of bits of tallow. Fire at say 3 yards from plank. If you don't miss aim, there will be a hole torn, about 2 inches in diameter.-The WrITER of "Physies without Apparatus."]

$\sqrt{-I}$ must send his name and address.

\section{THUNDERSTORMS}

II.

BEFORE I can go farther with this subject it is necessary that I should give some simple facts and illustrations connected with ordinary machine electricity. These will enable you to follow easily the slightly more I Abstract of a lecture, delivered in the City Hall, Glasgow, by Prof Tait. difficult steps in this part of our subject which remain to be taken.

Since we are dealing mainly with motion of electricity, it is necessary to consider to what that motion is due. You all know that winds, i.e. motions of the air, are due to differences of pressure. If the pressure were everywhere the same at the same level we should have no winds. Similarly the cause of the motion of heat in a body is difference of temperature. When all parts of a body are at the same temperature there is no change of distribution of heat. Now electricity presents a precisely analogous case. It moves in consequence of difference of potential. Potential, in fact, plays, with regard to electricity, a part precisely analogous to the rôle of pressure, or of temperature, in the case of motions of fluids and of conducted heat. Now the power of an electrical machine may be measured by the utmost potential it can give to a conductor. The greater the capacity of the conductor the longer time will be required for the machine to charge it; but no electricity passes between two conductors charged to the same potential. Hence the power of a machine is to be measured by using the simplest form of conductor, a sphere, and finding the utmost potential the machine can give it. It is easily shown that the potential of a solitary sphere is directly as the quantity of electricity, and inversely as the radius. Hence electricity is in equilibrium on two spheres connected by a long thin wire when the quantities of electricity on them are proportional -not to their surfaces, nor to their volumes, as you might imagine-to their radii. In other words, the capacity is proportional to the radius. This, however, is only true when there are no other conductors within a finite distance. When a sphere is surrounded by another concentric sphere, which is kept in metallic connection with the ground, its capacity is notably increased, and when the radii of the spheres are nearly equal the capacity of the inner one is directly as its surface, and inversely as the distance between the two spheres. Thus the capacity is increased in the ratio of the radius of one sphere to the difference of the radii of the two, and this ratio may easily be made very large. This is the principle upon which the Leyden jar depends.

It is found that the work required to put in a charge is proportional to the square of the charge. Conversely, the damage which can be done by the discharge, being equal to the work required to produce the charge, is proportional to the square of the charge, and inversely to the capacity of the receiver. Or, what comes to the same thing, it is proportional to the square of the potential and to the capacity of the conductor directly. Thus a given quantity of electricity gives a greater shock the smaller the capacity of the conductor which contains it. And two conductors, charged to the same potential, give shocks proportional to their capacities. But in every case, a doubling of the charge, or a doubling of the potential, in any conductor, produces a fourfold shock.

The only other point I need notice is the nature of the distribution of electricity on a conductor. I say on a conductor, because it is entirely confined to the surface. Its attractions or repulsions in various directions exactly balance one another at every point in the substance of the conductor. It is a most remarkable fact that this is always possible, and in every case in one way only. When the conductor is a single sphere the distribution is uniform. When it is elongated the quantity of electricity per square inch of its surface is greater at the ends than in the middle; and this disproprotion is greater the greater is the ratio of the length to the transverse diameter. Hence on a very elongated body, terminating in a point, for instance, the electric density-that is, the quantity per square inch of surface-may be exceedingly great at the point while small everywhere else. Now in proportion to the square of the electric density is the outward pressure of the electricity tending to escape by forcing a passage 